\title{
Optic Neuritis and Hypophysitis: Partial Remission after Pulse Therapy
}

\author{
Isabela Morales Cozeto ${ }^{1}$, Lívia Norcia Zenerato, Letícia Alarcão Max- \\ ta $^{2}$, Ricardo Baer Filho' ${ }^{1}$ Érico Paulo Heilbrun ${ }^{3}$, Márcio Luis Duarte ${ }^{4,5}$ \\ and Lucas Ribeiro dos Santos ${ }^{3,5 *}$ \\ ${ }^{1}$ Medical Student at Medical Sciences, Faculty of Santos, Santos, São Paulo, Brazil \\ ${ }^{2}$ Endocrinologist at A.C. Camargo Center, São Paulo, Brazil \\ ${ }^{3}$ Professor of Endocrinology, Medical Sciences, Faculty of Santos, Santos, São \\ Paulo, Brazil \\ ${ }^{4}$ Radiologist, Medical Residency Coordinator at Webimagem, São Paulo, Brazil \\ ${ }^{5}$ Masters in Evidence Based Health by UNIFESP, São Paulo, Brazil
}

*Corresponding Author: Lucas Ribeiro dos Santos, Professor of Endocrinology,

Medical Sciences, Faculty of Santos, Santos, São Paulo, Brazil.

\begin{abstract}
Lymphocytic or autoimmune hypophysitis $(\mathrm{AH})$ is a rare disorder characterized by inflammation of the pituitary gland. There is no consensus on treatment, but may include corticosteroid therapy and decompression surgery. Optic neuritis (ON) is an inflammation of the optic nerve, both of unknown etiology and autoimmune hypothesis. The association of pathologies is rare, with few reports in the literature. The diagnosis of $\mathrm{ON}$ is clinical and treatment with high dose corticosteroids. A case initially diagnosed as ON with pituitary macroadenoma is described: 55-year-old woman with sudden bilateral visual loss associated with nausea, vomiting, diarrhea and hypotension, MRI with pituitary expansive lesion with optic chiasm compression and laboratory tests showing thyrotrophic, corticotrophic and gonadotropic axes deficiencies, associated with mild hyperprolactinemia. Methylprednisolone pulse therapy was performed for ON treatment. Patient presented improvement of visual acuity, decreased pituitary volume and recovery of corticotrophic axis, raising the hypothesis of AH. The case demonstrates the importance of careful neuro-ophthalmologic and radiographic evaluation of patients with pituitary adenoma and visual loss. NO and AH should be considered in the differential diagnosis as this may prevent unnecessary invasive procedures.
\end{abstract}

Keywords: Autoimmune Hypophysitis; Optic Neuritis; Pituitary Diseases; Hypopituitarism

\section{Introduction}

Lymphocytic or autoimmune hypophysitis $(\mathrm{AH})$ is a rare disorder characterized by inflammation of the pituitary gland that can cause different degrees of pituitary dysfunction depending on the region affected $[1,2]$. It is a comorbidity in $25-50 \%$ with autoimmune conditions, such as Hashimoto's thyroiditis and Diabetes insipidus, which raises the hypothesis of autoimmune etiology $[1,3,4]$.

Most of the symptoms are due to the mass effect by the inflammatory process, causing severe headaches and visual field deficits due to optic chiasm compression [1,4]. Magnetic resonance imaging (MRI) shows diffuse and homogeneous seal mass but can be similar to adenomas and other pituitary tumors, making it difficult to differentiate [5]. The conclusive diagnosis is made by lesion bi- opsy, showing $\mathrm{T}$ cells lymphocytic infiltrate, edema, and pituitary fibrosis [1]. As it is an invasive method, some cases will be conducted as a presumptive diagnosis.

The main goals in HA treatment are to reduce the size of the pituitary gland and replace hormones deficiency; for such, drugs, surgery and radiotherapy may be used. Glucocorticoids have a dual function of reducing the inflammatory process and supplying adrenal deficiency [4] and high doses may yield a better response $[5,6]$.

Also of unknown etiology and autoimmune hypothesis, optic neuritis $(\mathrm{ON})$ is an inflammation of the optic nerve; it is the second most common cause of optic nerve alteration in people under 50 years $[7,8]$. ON may be the initial manifestation of multiple sclerosis or IgG4 syndrome, but many cases remain without definite etiology [7]. The diagnosis is clinical: sudden loss of sight, accom- 
panied by tenderness and painful eye movement $[7,8]$. Treatment is made through pulse glucocorticoid therapy, but often causes irreversible visual sequelae [7].

We describe a case initially diagnosed as $\mathrm{ON}$ associated with an incident macroadenoma, that had a change in the hypothesis to a probable autoimmune hypophysitis associated with ON.

\section{Case Report}

An informed consent was obtained from the patient prior to this report; a 55-year-old woman presented to the Santos City Emergency Room in 2017 with a sudden bilateral visual loss associated with nausea, vomiting, diarrhea, and hypotension; she had a history of systemic arterial hypertension and type 2 diabetes mellitus. Physical examination showed a heart rate of $96 \mathrm{bpm}$, blood pressure of $70 \times 50 \mathrm{mmHg}$ and bilateral amaurosis with no extrinsic eye motor deficits or pain on movement; patient was, then, referred to the Santa Casa de Santos neurology department, where she underwent a MRI (Figure 1) and laboratory analysis (Table 1).

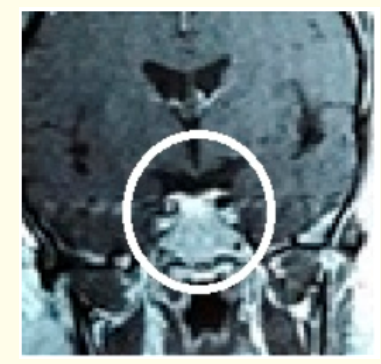

Figure 1: T1 weighted-image with contrast MRI in the coronal section demonstrating Expansive pituitary lesion of $1.8 \times 1.8 \times 1.5$ $\mathrm{cm}$ and impregnation of paramagnetic contrast in the sheath of intracranial optic nerves.

\begin{tabular}{|l|c|c|c|}
\hline \multicolumn{1}{|c|}{ Exam } & $\begin{array}{c}\text { Pre pulse } \\
\text { therapy }\end{array}$ & $\begin{array}{c}\text { Post pulse } \\
\text { therapy }\end{array}$ & $\begin{array}{c}\text { Normal } \\
\text { Values }\end{array}$ \\
\hline TSH & $0.47 \mathrm{mU} / \mathrm{L}$ & $0.71 \mathrm{mU} / \mathrm{L}$ & $0,5-4,5 \mathrm{mU} / \mathrm{L}$ \\
\hline Free T4 & $0.48 \mathrm{mg} / \mathrm{dL}$ & $0.72 \mathrm{mg} / \mathrm{dL}$ & $0,8-1,8 \mathrm{mg} / \mathrm{dL}$ \\
\hline $\mathrm{LH}$ & $<0.2 \mathrm{mIU} / \mathrm{dL}$ & $0.54 \mathrm{mIU} / \mathrm{dL}$ & $\begin{array}{c}\text { Menopause: } \\
>20 \mathrm{mIU} / \mathrm{dL}\end{array}$ \\
\hline FSH & $<3.0 \mathrm{mIU} / \mathrm{dL}$ & $2.36 \mathrm{mIU} / \mathrm{mL}$ & $\begin{array}{c}\text { Menopause: } \\
>30 \mathrm{mIU} / \mathrm{dL}\end{array}$ \\
\hline Prolactin & $44 \mathrm{ng} / \mathrm{mL}$ & $27.20 \mathrm{ng} / \mathrm{mL}$ & $5-25 \mathrm{ng} / \mathrm{mL}$ \\
\hline ACTH & - & $25 \mathrm{pg} / \mathrm{mL}$ & $10-46 \mathrm{pg} / \mathrm{mL}$ \\
\hline $\begin{array}{l}\text { Basal } \\
\text { Cortisol }\end{array}$ & $3.0 \mathrm{ug} / \mathrm{dL}$ & $14.2 \mathrm{ug} / \mathrm{dL}$ & $3-18 \mathrm{ug} / \mathrm{dL}$ \\
\hline IGF-1 & $57.3 \mathrm{ng} / \mathrm{dL}$ & $65.6 \mathrm{ng} / \mathrm{dL}$ & $84-236 \mathrm{ng} / \mathrm{dL}$ \\
\hline
\end{tabular}

Table 1: Laboratory findings.
Laboratory findings led to a probable diagnosis of thyrotrophic, corticotrophic and gonadotrophic axis deficiencies, associated with mild hyperprolactinemia (probable stalk effect).

The hypotheses of pituitary macroadenoma and optic neuritis was, then, raised, and it was decided to perform pulse therapy with methylprednisolone, and afterwards, surgically approach the pituitary macroadenoma; patient was also started on levothyroxine 75 mcg and was latter discharged on prednisone $5 \mathrm{mg}$ per day.

After pulse therapy, the patient showed partial improvement in visual acuity and the control MRI showed a pituitary with small heterogeneous parenchyma, prominence of the optic chiasm and optic nerve bilaterally (Figure 2). Due to this shift in the clinical picture, the patient was referred to the endocrinology service of the Guilherme Álvaro Hospital.

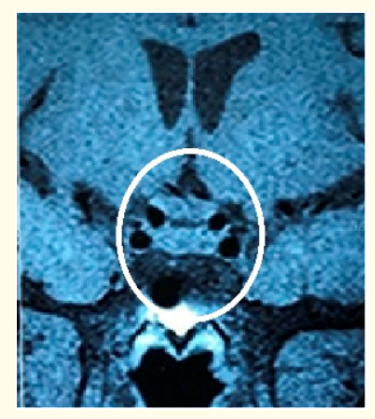

Figure 2: T1 weighted-image without contrast MRI in the coronal section demonstrating reduction of the pituitary gland, comparing with figure 1 , without compressing the optic chiasm (white circle).

In the meantime until the assessment of our team (2 months), the patient discontinued the use of prednisone on his own, keeping only levothyroxine; despite this, she had no symptoms of adrenal insufficiency, and so a second evaluation of pituitary function was performed (Table 1).

The reduction in pituitary volume associated with recovery of the corticotrophic axis then pointed to the probable hypothesis of lymphocytic hypophysitis. Levothyroxine dose was then increased to $88 \mathrm{mcg}$ per day and prednisone was suspended with guidance on its use in case of symptoms of adrenal insufficiency or predisposing conditions.

\section{Discussion}

As in $\mathrm{AH}, \mathrm{ON}$ has no clear cause, but their concomitant development suggests a common and probable etiology of autoimmunity; this association could be explained by the proximity of the optic chiasm to the Turkish saddle, facilitating the spread of the inflammatory process. 
Performing a search on medline, yielded seven reports of this association [10-16]. In only one case was multiple sclerosis diagnosed as the cause of optic neuritis [11]. AH and multiple sclerosis share an autoimmune background; also, multiple sclerosis may present other endocrinological disorders, so differential diagnosis is essential [11]. In this report, the hypothesis of multiple sclerosis was ruled out due to the absence of radiological and clinical signs.

AH presentation differs accordingly to the affected area and is subclassified as lymphocytic adenohypophysitis (anterior pituitary), lymphocytic infundibuloneurohypophysitis (posterior pituitary and infundibulum), and lymphocytic infundibulo-panhypophysitis (entire pituitary) [11]. In 5 of 6 cases, the involvement was posterior pituitary, with clinical diabetes insipidus [11-14,16], which is the dominant manifestation in the forms that reach this location. Only one case presented anterior pituitary involvement [10], as in the present report, with corticotrophic, gonadotrophic and thyrotrophic alterations, characterizing lymphocytic adenohypophysitis.

In all cases found, treatment was performed with corticotherapy, and only one reported the use of pulse therapy with methyl prednisolone [13] and one case associated the treatment with immunotherapy (rituximab) [16].

To date, there is no established protocol for the treatment of $\mathrm{AH}[2,5]$. Reduction in pituitary mass size and hormonal replacement should be performed. Pituitary mass effect can be reduced through corticotherapy, lymphocytic drugs, pituitary surgery or radiotherapy [2]. The use of immunotherapy is not stablished, but may be beneficial [16]. Surgery is only indicated in cases of: significant optic chiasm compression, inefficient response of corticosteroid therapy, or inability to establish a conclusive diagnosis by conservative methods [6].

In this report, due to $\mathrm{ON}$, the initial choice was pulse therapy with methylprednisolone. However, pulse therapy resulted in a significant improvement in the pituitary condition, arising the hypothesis of AH. The therapy chosen was analyzed in a prospective study by Kristof RA, which showed that the use of high-dose methylprednisolone pulse therapy in the short term is a good option in hypertension and has fewer side effects than chronic corticosteroid use [6].

\section{Conclusion}

This report described shows the importance of AH suspicion in atypical cases of pituitary adenoma. Confirmatory diagnosis is exclusively histological, but presumption was made by clinical evolution.
The presence of pituitary enlargement and visual loss should not always be attributed to compression of the optic chiasm. The association of $\mathrm{ON}$ and $\mathrm{AH}$ is rare, but this case shows that it might be underdiagnosed, and should clinicians should have a high level of suspicion, as this may prevent unnecessary invasive procedures.

\section{Bibliography}

1. Rivera J. "Lymphocytic hypophysitis: Disease spectrum and approach to diagnosis and therapy". Pituitary 9.1 (2006): 35-45.

2. Caturegli P., et al. "Autoimmune Hypophysitis". Endocrine Reviews 26.5 (2005): 599-614.

3. Paiva I., et al. "Hipofisite Auto-imune ou Linfocitica". Acta Medica Portuguesa (2003).

4. Dhooria B., et al. "A case of hypophysitis in a young male patient". Medical Journal Armed Forces India 74.1 (2018): 89-92.

5. Iuliano $\mathrm{S}$ and Laws E. "The diagnosis and management of lymphocytic hypophysitis". Expert Review of Endocrinology and Metabolism 6.6 (2011): 777-783.

6. Kristof R., et al. "Lymphocytic hypophysitis: non-invasive diagnosis and treatment by high dose methylprednisolone pulse therapy?" Journal Neurology Neurosurgery Psychiatry 67.3 (1999): 398-402.

7. Gal R., et al. "Corticosteroids for treating optic neuritis". Cochrane Database of Systematic Reviews 14.8 (2015): CD001430.

8. "The Clinical Profile of Optic Neuritis". Archives of Ophthalmology 109.12 (1991):1673.

9. Sellner, J., et al. "EFNS guidelines on diagnosis and management of neuromyelitis optica". European Journal of Neurology 17.8 (2010): 1019-1032.

10. Zoeller G., et al. "Lymphocytic hypophysitis in a patient presenting with sequential episodes of optic neuritis". Pituitary 15.1 (2010): 101-105.

11. Pena J., et al. "Lymphocytic Hypophysitis Associated With Pediatric Multiple Sclerosis". Pediatric Neurology 51.4 (2014): 580-582.

12. Tamiya N Saeki and A Mizota A. "Lymphocytic infundibuloneurohypophysitis associated with recurrent optic neuritis". British Journal of Neurosurgery 15.2 (2001):180-183.

13. Saito S., et al. "A case of optic neuritis associated with lymphocytic hypophysitis revealed by pattern-reversal VEP". Rinsho Shinkeigaku 51.1 (2011): 27-31. 
14. Imura H., et al. "Lymphocytic Infundibuloneurohypophysitis as a Cause of Central Diabetes Insipidus". New England Journal of Medicine 329.10 (1993): 683-689.

15. Al-Mujaini A., et al. "Lymphocytic infundibulo-neurohypophysitis: An unusual cause of recurrent optic neuropathy in a child". Journal of American Association for Pediatric Ophthalmology and Strabismus, 13.2 (2009): 207-209.

16. Xu C., et al. "Autoimmune lymphocytic hypophysitis in association with autoimmune eye disease and sequential treatment with infliximab and rituximab". Pituitary 18.4 (2014): 441447.

\section{Assets from publication with us}

- Prompt Acknowledgement after receiving the article

- Thorough Double blinded peer review

- Rapid Publication

- Issue of Publication Certificate

- High visibility of your Published work

Website: www.actascientific.com/

Submit Article: www.actascientific.com/submission.php

Email us: editor@actascientific.com

Contact us: +919182824667 